\title{
Thoracoscopy: Outstanding Interventional Modality in Diagnosis of Pleural Nosologies
}

\author{
I. Sotiriou, N. Siddique \\ Kettering General Hospital, Northamptonshire, UK \\ Email: giasotiriou@yahoo.gr
}

Received 25 August 2014; revised 24 September 2014; accepted 23 October 2014

Copyright (C) 2014 by authors and Scientific Research Publishing Inc.

This work is licensed under the Creative Commons Attribution International License (CC BY). http://creativecommons.org/licenses/by/4.0/

c) (i) Open Access

\begin{abstract}
Thoracoscopy is a well established invasive method for the diagnosis and management of pleural nosologies. The role and the impact that this procedure exerts in settings alongside the diagnostic yield in pleural malignancies are unquestionable. New insights and novel techniques promise an even greater future towards the usefulness of this technique in interventional pneumonology. This is a short review highlighting the principles and novel aspects in the evolutionary progress of pleuroscopy.
\end{abstract}

Keywords

Thoracoscopy, Cancer, Pleural Effusion, Autofluorescence

Thoracoscopy is the oldest invasive method in the modern pleural diagnostics. More than a century has passed since 1910, when the Swedish physician Hanz-Christian Jacobaeus pioneered with his evolutionary approach in tuberculosis pleurisy. He achieved the lysis of intrapleural adhesions through intracavitary insertion of his cystoscope and artificially inducted pneumothorax as therapeutic maneuver [1]. Ever since thoracoscopy has been abandoned as a therapeutic modality for tuberculosis, but its role has been elucidated in a vast of pleural disorders.

Thoracoscopy is a simple and safe procedure. As an interventional procedure is performed by a chest physician in the endoscopy suite, under local anesthesia and adequate sedation of the patient. The patient is positioned in lateral decubitus position, depending on the side of pleural effusion being under continuous monitoring of vital signs $\left(\mathrm{SpO}_{2}\right.$, blood pressure, heart rate, respiratory rate and heart rythm).

The diagnostic accuracy with regard to the patients with malignant pleural effusions undergoing thoracoscopy, is 95\% [2] [3]. On the other hand the yield of success of the particular procedure in their management with pneumothorax or either talk poudrage is ranging between $90 \%$ and $95 \%$ respectively [4].

The cornerstone instrument for the application of thoracoscopy is the rigid endoscope. In the recent years the 
role of the flexible bronchoscope has gradually gained his role in the terrain of invasive pleural diagnostic procedures. It is quite efficacious in context with the mediastinum and diaphragm access but the flexibility that possess is the "Achilles heel" keeping with the instruments handling and facilitating biopsies [5].

The $20^{\text {th }}$ century is being hailed as a milestone in relation to the introduction of new instrumentarium in the field of pleural diseases diagnostics. In the early 90s a pioneer novel instrument, the semiflexible (or semirigid or flex-rigid) thoracoscope, was successfully introduced for the management of patients with pleural effusions of unknown origin. The autoclavable semirigid thoracoscope has immense potential in the diagnosis and management of pleural disease. Its diagnostic accuracy in pleural disease is comparable to the rigid thoracoscope. It is also compatible with existing video processors and light sources available in most endoscopy suites. Pleuroscopy using rigid or semirigid instruments allows visualization of the parietal, and visceral pleura. Despite that fact, the posterior and mediastinal aspects of the hemithorax are topographically difficult for access and biopsy sampling, if the lung is partially collapsed or in the presence of adhesions between the lung parenchyma and chest wall [6] [7].

In contrast, the semirigid pleuroscope, which combines the flexibility of the fiberoptic bronchoscope and the rigidity of conventional thoracoscope, overcomes the limited view by easy manoeuvrability of its nimble tip around the adhesions [8] [9].

The main drawback of the use of the semirigid endoscope is the lack of obtaining a substantial quantity of tissue sample. That is due to the dimension of the biopsy needle which is similar to the one used in the flexible bronchoscope. That issue is mandatory for diseases such as mesothelioma and lung cancer, where the diagnostic yield rises in context of the number and volume of samples as well [6].

Thoracoscopy in the late years has definitely established its role as an invasive diagnostic procedure. The prognosis of potentially resectable non-small cell lung cancer (NSCLC) is directly related to the pathologic stage of the disease at presentation [10].

If facing a confirmation of pleural involvement the patient is inoperable (M1a) and this per se alters the prognosis and further management of the patient as well [11]. In the era of the modern histopathology and the different molecular techniques, such as Epidermal Growth Factor Receptor (EGFR) that widely being used for the discrimination of the different types of cancer, the role of thoracoscopy, once more, has gained its throne. It is also a fact and widely acceptable that the blind transthoracic biopsy is in cases of differentiation of malignant mesothelioma with lesser diagnostic and prognostic yield than the thoracoscopic biopsies [12].

The role of thoracoscopy has the same importance in research field as in clinical settings. A great number of new insights have been reached out in context with the pleural nosology. Autofluorescence endoscopy is a technique used in clinical settings for the detection of neoplastic tissue alterations. Its use based on the axiom that neoplastic epithelial cells could reflect a light of a wavelength which would be dissimilar in frequency to the one that has been produced by the normal epithelium. The sensitivity of autofluorescence thoracoscopy for detecting malignant lesions on the pleural surface was $100 \%$ and the specificity was $75 \%$ [13].

Fluorescein-enhanced autofluorescence thoracoscopy was used to shed light in the aspect of pathophysiology of the pleural permeability as well. The findings suggest that the location of the pathology origin in spontaneous pneumothorax is not focal in nature. In contrast it is a matter of imbalance in pleural porosity [14]. Many aspects with regard to neoagiogenesis and molecular level in pleural disorders have been elucidated by the pleuroscopy technique. The role of different growth factors such as vascular endothelial growth factor (VEGF), has been well established in the era of thoracoscopy [15].

A century has already passed since the initial introduction of thoracoscopy/pleuroscopy in the modern medical history. Gradually and steadily, this extraordinarily invasive procedure has gained its role in the field of diagnosis and management of pleural disorders. The introduction of novel techniques seals the notion that the future of the procedure will become even brighter. The benefits that already have been documented through the currently existing trials have underlined the necessity that the continuous research is mandatory and crucial in the upcoming years.

\section{References}

[1] Moisiuc, F.V. and Colt, H.G. (2007) Thoracoscopy: Origins Revisited. Respiration, 74, 344-355. http://dx.doi.org/10.1159/000098235

[2] Rodriguez-Panadero, F. (2008) Medical Thoracoscopy. Respiration, 76, 363-372. http://dx.doi.org/10.1159/000158545 
[3] Froudarakis, M.E. (2008) Diagnostic Work-Up of Pleural Effusions. Respiration, 75, 4-13. http://dx.doi.org/10.1159/000112221

[4] Noppen, M. and De Keukeleire, T. (2008) Pneumothorax. Respiration, 76, 121-127. http://dx.doi.org/10.1159/000135932

[5] Davidson, A.C., George, R.J., Sheldon, C.D., Sinha, G., Corrin, B. and Geddes, D.M. (1988) Thoracoscopy: Assessment of a Physician Service and Comparison of a Flexible Bronchoscope Used as a Thoracoscope with a Rigid Thoracoscope. Thorax, 43, 327-332. http://dx.doi.org/10.1136/thx.43.4.327

[6] Lee, P. and Colt, H.G. (2005) Rigid and Semirigid Pleuroscopy: The Future Is Bright. Respirology, 10, 418-425. http://dx.doi.org/10.1111/j.1440-1843.2005.00737.x

[7] Froudarakis, M.E. and Noppen, M. (2009) Medical Thoracoscopy: New Tricks for an Old Trade. Respiration, 78, 373374. http://dx.doi.org/10.1159/000243553

[8] Ernst, A., Hersh, C.P., Herth, F., et al. (2002) A Novel Instrument for the Evaluation of the Pleural Space: An Experience in 34 Patients. Chest, 122, 1530-1534. http://dx.doi.org/10.1378/chest.122.5.1530

[9] McLean, A.N., Bicknell, S.R., McAlpine, L.G. and Peacock, A.J. (1998) Investigation of Pleural Effusion: An Evaluation of the New Olympus LTF Semiflexible Thoracofiberscope and Comparison with Abram’s Needle Biopsy. Chest, 114, 150-153. http://dx.doi.org/10.1378/chest.114.1.150

[10] Mountain, C.F. (1986) A New International Staging System for Lung Cancer. Chest, 89, 225S-233S. http://dx.doi.org/10.1378/chest.89.4 Supplement.225S

[11] Froudarakis, M.E. (2009) Diagnosis and Management of Pleural Effusion in Lung Cancer. In: Bouros, D., Ed., Pleural Diseases, 2nd Edition, Informa, New York, 427-447.

[12] Scherpereel, A., Astoul, P., Baas, P., et al. (2010) Guidelines of the European Respiratory Society and the European Society of Thoracic Surgeons for the Management of Malignant Pleural Mesothelioma. European Respiratory Journal, 35, 479-495. http://dx.doi.org/10.1183/09031936.00063109

[13] Chrysanthidis, M.G. and Janssen, J.P. (2005) Autofluorescence Videothoracoscopy in Exudative Pleural Effusions: Preliminary Results. European Respiratory Journal, 26, 989-992. http://dx.doi.org/10.1183/09031936.05.00027505

[14] Noppen, M. and De Keukeleire, T. (2008) Pneumothorax. Respiration, 76, 121-127. http://dx.doi.org/10.1159/000135932

[15] Zhou, W.-B., Bai, M. and Jin, Y. (2009) Diagnostic Value of Vascular Endothelial Growth Factor and Endostatin in Malignant Pleural Effusions. The International Journal of Tuberculosis and Lung Disease, 13, 381-386. 
Scientific Research Publishing (SCIRP) is one of the largest Open Access journal publishers. It is currently publishing more than 200 open access, online, peer-reviewed journals covering a wide range of academic disciplines. SCIRP serves the worldwide academic communities and contributes to the progress and application of science with its publication.

Other selected journals from SCIRP are listed as below. Submit your manuscript to us via either submit@scirp.org or Online Submission Portal.
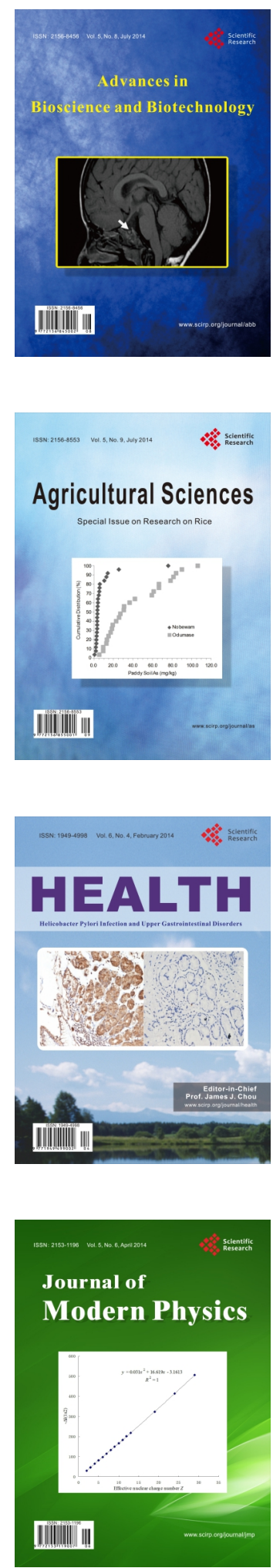
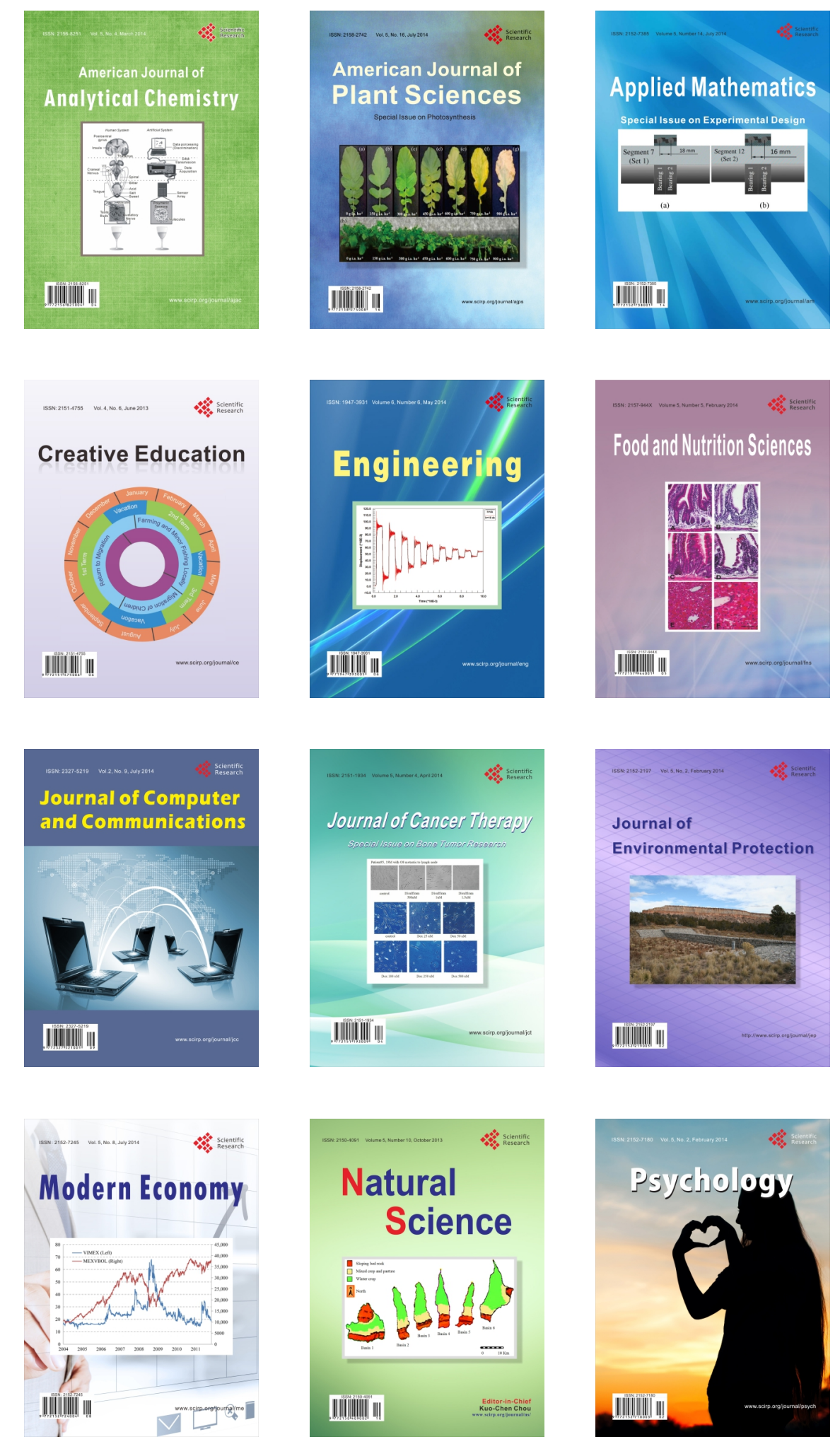